\title{
Zooplankton abundance during summer in the Bay of La Paz (southwestern Gulf of California, Mexico)
}

\author{
Erik Coria-Monter ${ }^{1}$, María Adela Monreal-Gómez ${ }^{1}$ \\ David Alberto Salas de León ${ }^{1}$ \& Elizabeth Durán-Campos ${ }^{1}$ \\ ${ }^{1}$ Instituto de Ciencias del Mar y Limnología, Universidad Nacional Autónoma de México \\ (UNAM), México \\ Corresponding author: Erik Coria-Monter (coria@ cmarl.unam.mx)
}

\begin{abstract}
Marine zooplankton play key roles in the transfer of energy to higher trophic levels and the removal of $\mathrm{CO}_{2}$ from the atmosphere through the sedimentation of inorganic and organic carbon compounds included in their fecal pellets. Therefore, differences in the zooplankton groups driven by climate variations could influence the biogeochemical cycles at large oceanic scales. As a contribution to this topic, we analyzed the zooplankton groups in the Bay of La Paz, Gulf of California, Mexico, a highly dynamic basin characterized by its high biological productivity. We used information gathered during multidisciplinary research cruises in the summers of 2008 and 2009. The results showed differences in the hydrographic parameters between both summers, with a higher temperature recorded in 2009. The zooplankton groups showed that the calanoid copepods were the most abundant; however, there were important differences in the relative abundance of the rest of the analyzed groups as an effect of the temperature distribution along the study area, which was confirmed by multivariate statistical methods. These temperature changes were associated with increased gelatinous zooplankton (Cnidaria, Chaetognatha, Appendicularia, and Ctenophora) in 2009 in a region where the temperature was higher, possibly as a result of changes in food (phytoplankton) availability.
\end{abstract}

Keywords: zooplankton community; copepods; distribution; temperature; Bay of La Paz; Gulf of California

\section{INTRODUCTION}

Zooplankton occupies key positions in the pelagic food web as either primary consumers or low-level predators. Indeed, they are also a key bottleneck of transferring the energy produced by phytoplankton to higher trophic levels, including high-commercial-value fish stocks (Richardson, 2008). Also, zooplankton contributes to removing $\mathrm{CO}_{2}$ from the atmosphere through the sedimentation of inorganic and organic carbon compounds in their fecal pellets (Brierley, 2017).

The distribution of zooplankton in the ocean is closely related to complex arrays of factors, including the presence of hydrodynamic processes at different scales (e.g., internal waves, eddies), the water column depth, the trophic status (i.e., productivity) of a particular region, and, mainly, the water temperature regime, which, in turn, determines the biological cycles, growth and metabolism rates of zooplankton.
Investigations of the effects of environmental factors on zooplankton composition contribute to understanding their population fluctuations by providing clues about whether certain groups may succeed under certain environmental conditions (Estrada et al., 2012).

The role of the physical environment in the distribution of zooplankton is also relatively well documented. For example, since the work of Backus et al. (1981), the cold-water masses associated with the cyclonic Gulf Stream rings have proven to be important for the horizontal and vertical distribution of zooplankton in the upper $800 \mathrm{~m}$ of the water column. Then, over the last decade, numerous studies on the role of physical forcing factors on the zooplankton community have been conducted around the globe. Among these, Estrada et al. (2012) analyzed the zooplankton community structure in Hudson Bay (Canada) and showed that the hydrological and hydrodynamic conditions (salinity, stratification, mixing, and temperature) could have significant effects on zooplankton

Corresponding editor: Sergio Palma 
spatial distribution. In the Gulf of California, high zooplankton biomass, mostly represented by Copepoda, Chaetognatha, and Euphausiacea, was associated with cold-water masses, where dense chlorophyll- $a$ patches also support high zooplankton biomass (Salas de León et al., 2011). In the southern Gulf of California, during summer, the occurrence of mesoscale structures, such as fronts and eddies, affected the sea surface temperature (SST) distribution, with values $>28^{\circ} \mathrm{C}$ (Lavín et al., 2009). In this region, the influence of different environmental variables on particular zooplankton groups was previously reported, showing that the zooplankton population dynamic and its response depends on the presence of physical structures with different scales that exert a significant influence over the euphausiids (Ambriz-Arreola et al., 2017), the mesopelagic fish larvae (Contreras-Catala et al., 2016), and the epipelagic copepods (Palomares-García et al., 2013). In the Bay of La Paz, a relationship between the abundance of zooplankton functional groups and the cold-water masses associated with a mesoscale cyclonic eddy has been documented, showing a radial distribution from the center of the eddy to the periphery, with the highest zooplankton biomass at the center. In particular, the changes in the temperature regime induced by the eddy retain a markedly different composition of the zooplankton, with a predominance of herbivorous taxa in the center and a higher proportion of omnivorous zooplankton at the periphery. In contrast, the carnivorous zooplankton was observed to be in high abundance in connection with the Gulf (Durán-Campos et al., 2015).

Zooplankton ecology studies have progressively become crucial to understanding and predicting the impact of current (climate-driven) changes of the oceans, particularly in regions with high biological diversity, such as the Gulf of California and the Bay of $\mathrm{La} \mathrm{Paz}$. This area has been considered one of the most diverse and productive seas in the world, with a high number of emblematic endemic species, such as the totoaba (Totoaba macdonaldi), the mystery anchovy (Anchoviella parri), and the vaquita (Phocoena sinus). This high biodiversity is close related with the confluence of several hydrodynamic processes at different scales; for this reason, the region has been considered one of the largest marine ecosystems of the world (Páez-Osuna et al., 2016; Mercado-Santana et al., 2017; Coria-Monter et al., 2018), and, since 2005, it is entitled as a UNESCO World Heritage site (Silverberg et al., 2014). Not only the Gulf is unique in terms of biodiversity, but it also has economic importance due to its support of high-value commercial species for the fishery industry, including tuna, sardines, squid, and shrimp, together totaling $60 \%$ of
Mexico's annual catch (Arreguín-Sánchez et al., 2017). Additionally, due to the pristine beaches, reefs, and wildlife, the Gulf draws over a million tourists each year (Johnson et al., 2019). It is an important ecological region, as it represents a site for either the refuge or feeding of several species (Pardo et al., 2013). The climate is semiarid, with evaporation $\left(300 \mathrm{~mm} \mathrm{yr}^{-1}\right)$ that exceeds precipitation $\left(180 \mathrm{~mm} \mathrm{yr}^{-1}\right)$, and the rivers discharge is practically nil. The weather temperature during summer reaches $37^{\circ} \mathrm{C}$, while it is $\sim 10^{\circ} \mathrm{C}$ in winter. The bay interchanges water masses with the Gulf through two openings: Boca Grande, a broad and deep region located at the northern portion, and the San Lorenzo Channel, a narrow and shallow region in the south (Monreal-Gómez et al., 2001). The sea surface temperature field inside the bay presents an apparent seasonal variability (Durán-Campos et al., 2020), with values of $\sim 30^{\circ} \mathrm{C}$ during summer (Durán-Campos et al., 2019) and values of $\sim 19^{\circ} \mathrm{C}$ during winter (GarcíaMirafuentes, 2010). The circulation pattern inside the bay is dominated by the presence of a mesoscale cyclonic eddy (Monreal-Gómez et al., 2001), which induces a nutrient Ekman pump, fertilizing the euphotic zone (Coria-Monter et al., 2017). A phytoplankton differential distribution between diatoms and dinoflagellates has been observed in the eddy field (Coria-Monter et al., 2014), with a consequent differential zooplankton aggregation, mainly due to the food availability (Durán-Campos et al., 2015).

This study aims to assess the zooplankton groups during the summer of 2008 and 2009 in the Bay of La Paz, southern Gulf of California, Mexico. We focused our study over two consecutive summers to compare and explore any patterns in zooplankton distribution along the bay, with the hypothesis that there will be changes in the zooplankton groups due to changes in the temperature.

\section{MATERIALS AND METHODS}

\section{Study area and sampling}

The Gulf of California and adjacent areas (Fig. 1a), such as the Bay of La Paz, have high importance in terms of the planktonic species' productivity, abundance, and diversity. The Bay of La Paz (maximum depth $420 \mathrm{~m}$ ) is located at the southwestern portion of the Gulf of California, between $24^{\circ} 06^{\prime}-24^{\circ} 54^{\prime} \mathrm{N}$ and $110^{\circ} 18^{\prime}-118^{\circ} 48^{\prime} \mathrm{W}$, of which represents the biggest basin (Fig. 1b).

The hydrographic measurements and zooplankton samples were gathered during the oceanographic expedition's DIPAL-II and DIPAL-III, carried out from September 3 to 9, 2008, and August 13 to 17, 2009, respectively, onboard the R/V El Puma owned by the 

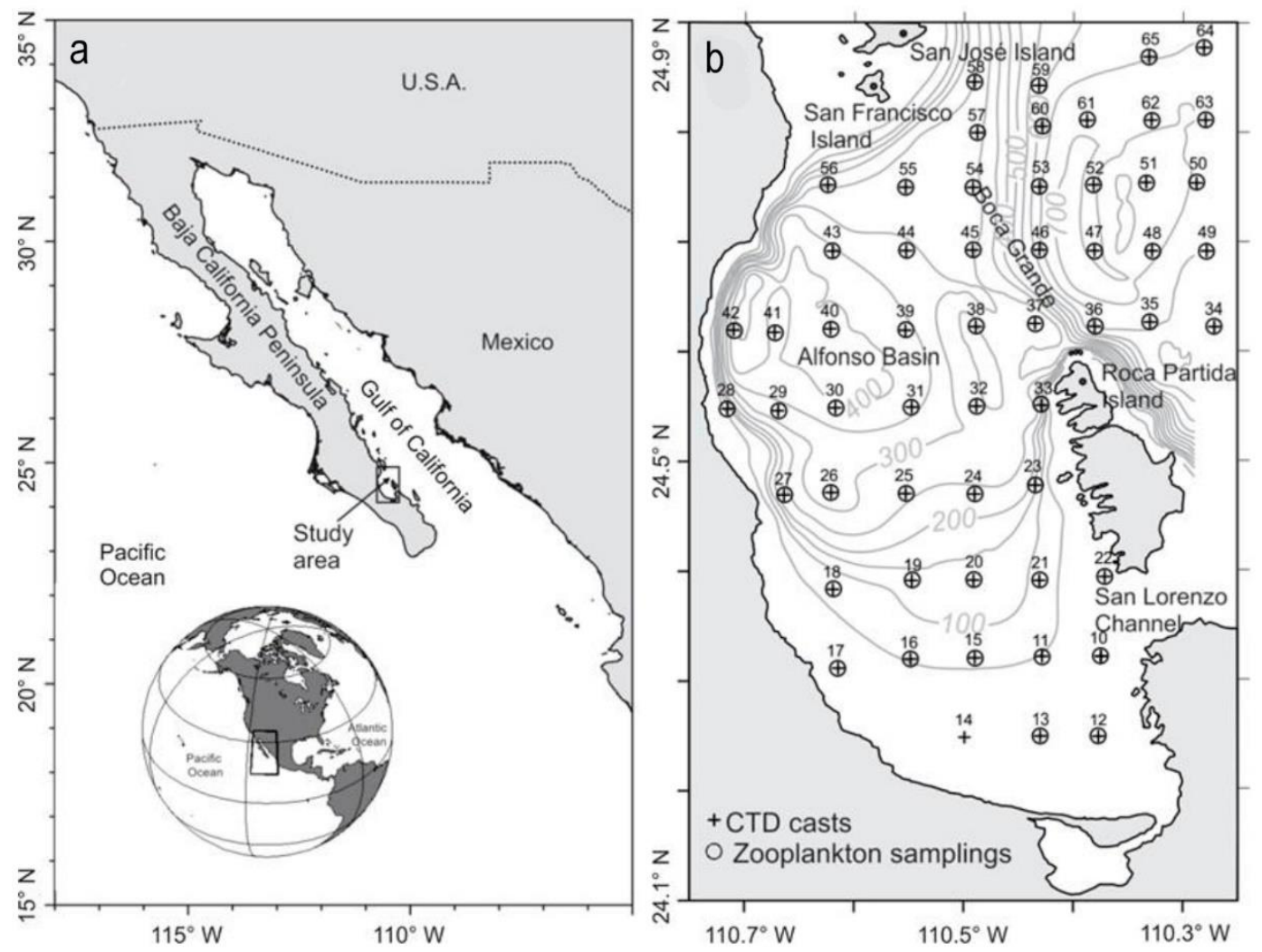

Figure 1. Study area: a) the Gulf of California, and b) Bay of La Paz. ${ }^{+}$Represents the hydrographic stations; o represents stations where oblique zooplankton hauls were performed. Bathymetry is shown in meters.

National Autonomous University of Mexico (UNAM). A total of 56 hydrographic stations were sampled, covering both the Bay of La Paz and the adjacent area in the Gulf of California (Fig. 1b).

At all stations, a conductivity, temperature, and depth probe (CTD, SeaBird 19 plus), equipped with a fluorescence sensor (ECO-Wet Labs) attached to a General Oceanics rosette system, was used to obtain high-resolution hydrographic records. The CTD casts were $\sim 5 \mathrm{~m}$ above the seafloor. The probe was lowered at a rate of $1 \mathrm{~m} \mathrm{~s}^{-1}$ to acquire data at $24 \mathrm{~Hz}$, with a temperature of $0.005^{\circ} \mathrm{C}$ and conductivity sensitivities of $0.0005 \mathrm{~S} \mathrm{~m}^{-1}$, respectively.

Immediately following the rosette cast, oblique zooplankton hauls (day and night-time) were carried out using bongo nets $(60 \mathrm{~cm}$ diameter in mouth and a $333 \mu \mathrm{m}$ mesh size) for $15 \mathrm{~min}$ at $\sim 2$ knots (Fig. 1b). In the 2008 oceanographic expedition, $48 \%$ of the stations sampled were carried out under light (day) conditions, and $52 \%$ were under dark (night) conditions; in 2009, $45 \%$ of the stations sampled were carried out under light conditions, and 55\% under dark conditions. With the use of nets with a $60 \mathrm{~cm}$ diameter in mouth and 333 $\mu \mathrm{m}$ mesh size, we assumed good representability of the mesozooplankton fraction in our samples, and we avoid the ease clogging of the net by phytoplankton or organic matter (MacGowan \& Fraundorf, 1996). After each tow, the nets were carefully inspected and washed with seawater. Zooplankton organisms were collected from $200 \mathrm{~m}$ depth to the surface. Calibrated General Oceanics mechanical flowmeters were used to calculate the water volume filtered. Onboard, the organisms were fixed with a solution of formalin with sodium borate at $4 \%$ for $24 \mathrm{~h}$ and then preserved in $70 \%$ ethanol into airtight glass bottles and in dark conditions. The samples consisted of a great variety of organisms, including mollusks, crustaceans, cnidarians, doliolids, appendicularians, ctenophores, chaetognaths, larval squids, larval fishes, among others.

\section{Data reduction}

The data obtained by the CTD probe were firstly processed with the manufacturer software (SBE Data Processing v.7.26.7) and averaged to 1 dbar. Finally, standard algorithms were used to derive the temperature $\left({ }^{\circ} \mathrm{C}\right)$, salinity, and density $\left(\mathrm{kg} \mathrm{m}^{-3}\right)$.

Satellite images of the SST and chlorophyll- $a(\mathrm{Chl}-a)$ concentration from the Moderate-Resolution Imaging Spectroradiometer (MODIS) were obtained during the dates when both research cruises took place for a comparison with the in situ measurements. Images with a $1 \mathrm{~km} /$ pixel spatial resolution were obtained from the 
NASA Ocean Color Group browser (https://oceancolor.gsfc.nasa.gov/). The processing method was as follows: First, using level 2 (before mapping), values of both variables were extracted with SeaDAS v.7.4. In order to screen insufficient -or low- quality data when generating the images, the flags/masks CLDICE, HILT, LAND, and STRAYLIGHT were applied following the protocols by Pieri et al. (2015).

\section{Laboratory analyses}

Each zooplankton sample was initially split sequentially using a Folsom splitter until reaching the curve's point with less variation, to count and identify organisms obtained at 1/32 of the total sample (Kramer et al., 1972). Then, using a Carl Zeiss microscope, the organisms were identified according to the major zooplankton groups following Trégouboff \& Rose (1957) and Boltovskoy (1999) using a Petri glass dish to observe under the microscope. The abundance of the collected material was standardized to $100 \mathrm{~m}^{3}$ following the protocols by Kramer et al. (1972) with the expression $N=N m / V \times 100$, where $N$ is the zooplankton abundance per $100 \mathrm{~m}^{3}$ water strained, $\mathrm{Nm}$ is the zooplankton collected in net tow, and $V$ is the cubic meters of water strained. We then calculated the relative abundance for each zooplankton group, which is the number of samples collected per group over the total number of organisms collected, expressed as a percentage.

\section{Data analyses}

Diversity is one of the most important parameters used to describe ecosystems. In this study, we computed the Shannon-Weaver diversity index $\left(H^{\prime}\right)$, which is one widely used index for comparing diversity between habitats, and it is enough to distinguish by groups (Magurran, 2004). The index was computed with the expression $H^{\prime}=-\sum_{n=1}^{n}(p i \times \ln p i)$ where $H^{\prime}$ is the diversity index, $p i$ is the proportion of each group in the sample, and $\ln p i$ is the natural logarithm of the proportion (Ortiz-Burgos, 2016). This index's value ranges from 1.0 to 4.0 , and its principal objective is to obtain a quantitative estimate of the biological variability and then compare this variability both in space and time (Ortiz-Burgos, 2016).

To explore the effect of the environmental variables measured by the CTD probe on the zooplankton groups analyzed, a canonical correspondence analysis (CCA) was performed. Following the protocols by Ter Braak (1986) and the standard routines for Canoco v.4.5 software, two matrices were implemented: one containing the square-root transformed abundance data for each zooplankton group by sampling station, and another one with the surface hydrographic data (e.g., temperature, salinity, density, Chl- $a$ concentration) obtained for each hydrographic station.

\section{RESULTS}

The hydrographic parameters and their distribution in the bay varied between the two sampling periods. During the summer of 2008 , at $2 \mathrm{~m}$ depth, the temperature showed values between 29.4 and $30.2^{\circ} \mathrm{C}$, while during 2009 , values ranged from 28.4 to $30.6^{\circ} \mathrm{C}$. The horizontal distribution of sea surface temperature also varied between the two study periods. More in detail, during 2008, there was a cold-core situated in the central part of the bay, reaching values of $29.4^{\circ} \mathrm{C}$ at its center, and high temperatures $\left(>30^{\circ} \mathrm{C}\right)$ were observed outside the bay (Fig. 2a). In 2009 fragmented cold cores occurred in the bay's central region with values of $\sim 29.3^{\circ} \mathrm{C}$ but characterized by slightly higher values than those observed in 2008. The surface temperature presented values of $\sim 28.4^{\circ} \mathrm{C}$, particularly in the southern part of the bay, close to the Gulf (Fig. 2b).

The patterns in surface temperature were confirmed by SST satellite images (Figs. 3a,c), while Chl- $a$ surface concentrations were characterized by clear north-to-south and cost-to-offshore gradients in both sampling periods, with higher values, observed close to the Gulf and in coastal areas $\left(>1 \mathrm{mg} \mathrm{m}^{-3}\right)$. In 2008, the relatively higher values of Chl- $a$ were observed in the central part of the bay (Fig. 3b), in coincidence with the cold core; in 2009, the distribution of the Chl- $a$ values followed a circular shape in the central part of the bay with values of $\sim 0.9 \mathrm{mg} \mathrm{m}^{-3}$ and the maximum values again observed close to the southern coast, reaching values of $1.3 \mathrm{mg} \mathrm{m}^{-3}$ associated to cold water (Fig. 3d).

Sixteen zooplankton groups were identified from the zooplankton samplings; these are summarized in Table 1. In terms of their relative abundance, the calanoid copepods were the most abundant group in both summers, representing 49 and $38 \%$ of total zooplankton abundance in 2008 and 2009, respectively, followed by cyclopoid copepods (24 and 37\%). The remaining taxa represented less than $10 \%$ cumulatively in both summers, with ctenophores as the least abundant group $(<1 \%)$.

Gelatinous zooplankton as cnidarians, chaetognaths, appendicularians, and ctenophores, were more abundant in 2009 than in 2008; these gelatinous organisms accounted for more than $11 \%$ in 2009 and only $6.8 \%$ in 2008 of the total zooplankton groups analyzed (Fig. 4). Based on their feeding behavior (except for appendicularians, mostly herbivores), the gelatinous organisms were carnivores. The ShannonWeaver index calculation showed a value of 1.67 in 2008 and 1.58 in 2009. 

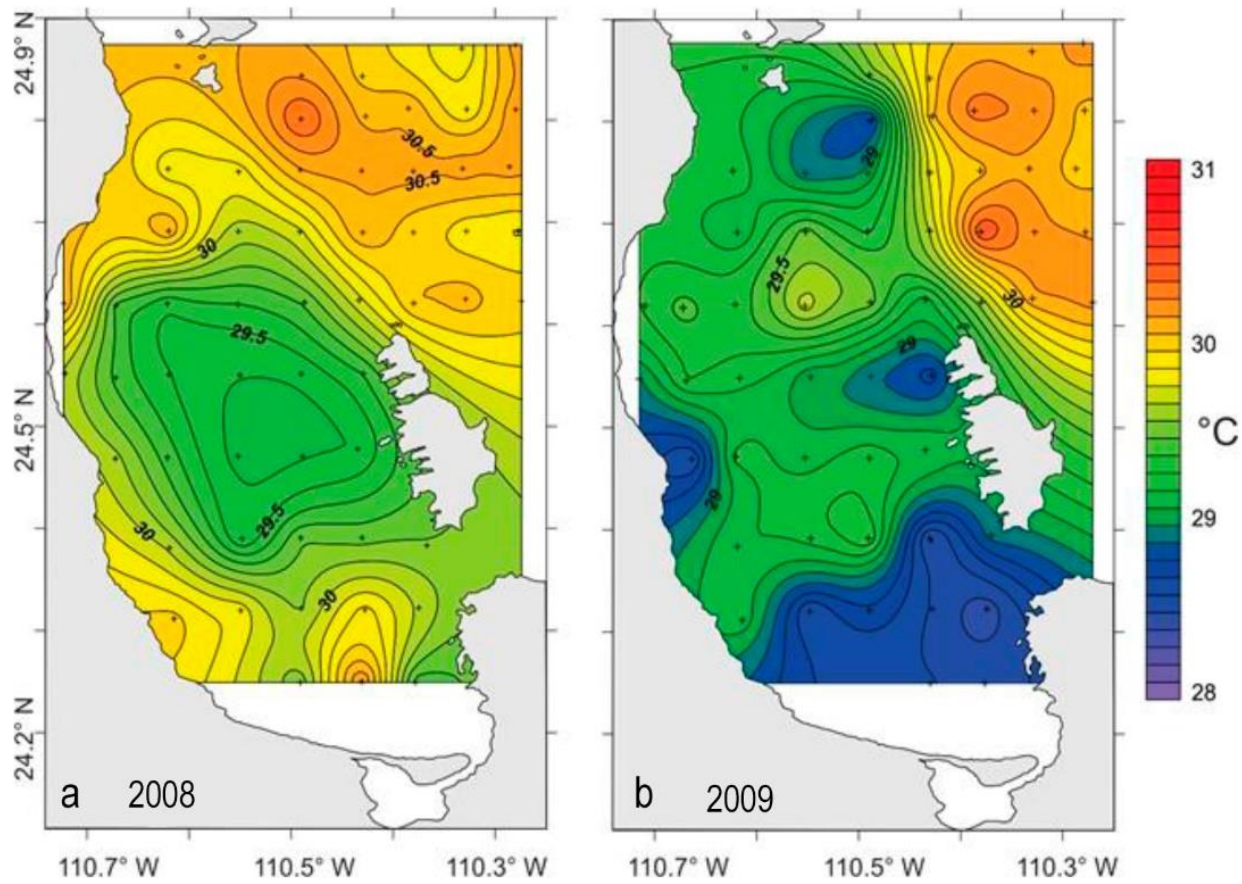

Figure 2. Surface distribution (at $2 \mathrm{~m}$ depth) of the temperature $\left({ }^{\circ} \mathrm{C}\right)$ during: a) summer of 2008 , and b) summer of 2009. Contour interval: $0.1^{\circ} \mathrm{C}$.

The differences presented in the spatial distribution of two target groups in this study (calanoid copepods and cnidarians) showed changes along the bay and between both summers analyzed (Fig. 4). During 2008, the calanoid copepods' maximum abundance $(3,900$ ind $100 \mathrm{~m}^{-3}$ ) was observed at the southern portion of the bay (Fig. 5a), while during 2009, the maximum abundances $\left(7,520\right.$ ind $\left.100 \mathrm{~m}^{-3}\right)$ were located at the central portion of the bay (Fig. 5b). An interesting pattern of distribution was observed for the cnidarians. In contrast, during 2008, the horizontal distribution showed their maximum values (470 ind $100 \mathrm{~m}^{-3}$ ) in the northern portion of the bay (Fig. 5c); during 2009, their abundances showed an increase, with the maximum values (>500 ind $100 \mathrm{~m}^{-3}$ ) observed close to the connection with the Gulf of California (Fig. 5d). In this region, the temperature distribution was higher during 2009.

The CCA ordination diagrams varied between both summers analyzed. In 2008, the dominant groups (calanoid and cyclopoid copepods) showed a relationship with the density values along the bay (which ranged from 21.5 to $22.5 \mathrm{~kg} \mathrm{~m}^{-3}$ ), as well as with the Chl- $a$ concentrations (which ranged from 0.2 to 1.3 $\mathrm{mg} \mathrm{m} \mathrm{m}^{-3}$ ), suggesting an elevated food concentration in the region that may influence the distribution of these organisms (Fig. 6a). During 2009, the CCA ordination diagram presented substantial changes concerning
2008, showing that the gelatinous zooplankton (Cnidaria, Chaetognatha, Appendicularia, and Ctenophora) was related with the temperature (Fig. 6b), which rose into a range from 28.4 to $30.4^{\circ} \mathrm{C}$ and confirms the distribution patterns observed (Fig. 5).

\section{DISCUSSION}

Copepods are probably the most numerous multicellular organisms on Earth. In the marine ecosystem, they play an essential role due to the position that they occupy in the trophic webs, and by their contribution to the removal of $\mathrm{CO}_{2}$ from the atmosphere through the sedimentation of inorganic and organic carbon compounds included in their fecal pellets, contributing to the appropriate functioning of the biological or carbon pump, which is why they have been the subject of interest in recent years (Richardson, 1980; Vidal, 1980; Mauchline et al., 1998; Durán-Campos et al., 2019). Calanoid copepods are of prime importance because many of them are herbivorous, feeding on phytoplankton to form a direct link between phytoplankton and the higher trophic levels pelagic food web, including commercially important fish (Mauchline et al., 1998). Although cyclopoid copepods are strictly carnivores, some species at some stages could feed phytoplankton, particularly diatoms (Turner, 1986; Paffenhöfer, 1993). Particularly in the southern Gulf of 


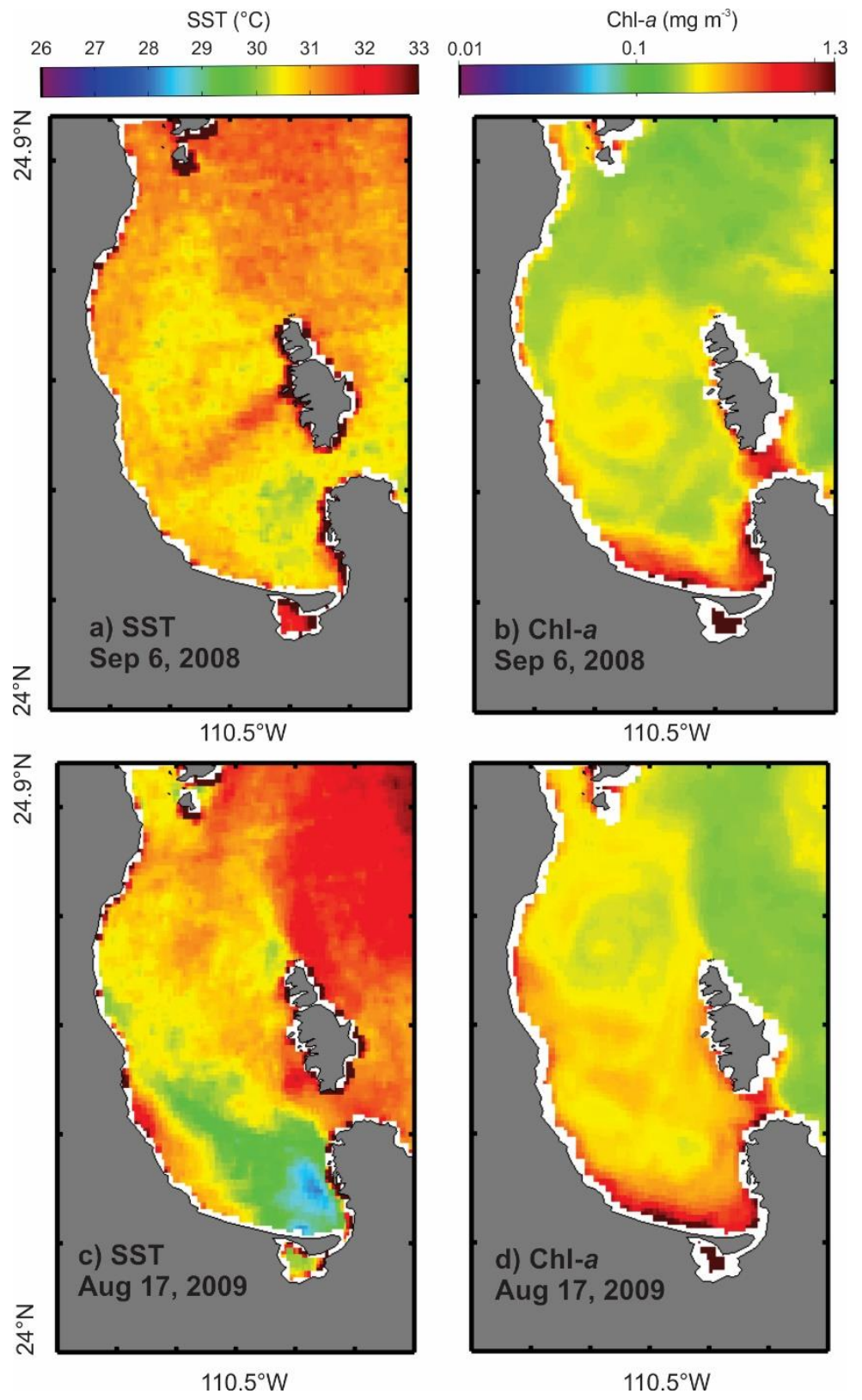

Figure 3. Satellite images from MODIS: on September 6, 2008 a) sea surface temperature $\left({ }^{\circ} \mathrm{C}\right)$, and b) chlorophyll- $a(\mathrm{mg}$ $\left.\mathrm{m}^{-3}\right)$; on August 17, 2009, c) sea surface temperature $\left.\left({ }^{\circ} \mathrm{C}\right), \mathrm{d}\right)$ chlorophyll- $a\left(\mathrm{mg} \mathrm{m}^{-3}\right)$.

California, calanoid copepods have been reported as the dominant group (Durán-Campos et al., 2015), and studies have evaluated their composition and distribution about hydrographic properties, as well as hydrodynamic processes. For example, CruzHernández et al. (2018) evaluated the distribution of calanoid copepods concerning the water column's thermal structure, showing that the most propitious conditions for their feeding occur in the thermocline. Those authors also revealed a clear relationship with the water column stratification and interpreted it as an adaptation strategy to survive there.
Our results revealed that calanoid copepods were the most abundant group during both summers, representing 49 and $38 \%$ of total zooplankton abundance in 2008 and 2009. However, significant differences $\left(\mathrm{R}^{2}=0.87, P<0.005\right)$ emerged in their relative abundances, not only for the Calanoid Copepods but also for the rest of the analyzed groups. We contend that such differences can be related to the hydrographic properties, and, particularly with the surface temperature distribution along the study area, which showed statistical significance $\left(\mathrm{R}^{2}=0.97, P<\right.$ 0.005 ) and an increment of $\sim 1.00^{\circ} \mathrm{C}$ during 2009 , parti- 
Table 1. Total abundance and their relative abundance of each analyzed zooplankton group during the summers of years 2008 and 2009.

\begin{tabular}{lcccc}
\hline \multirow{2}{*}{ Zooplankton group } & $\begin{array}{c}\text { Total abundance } \\
\text { (ind } 100 \mathrm{~m}^{-3} \text { ) }\end{array}$ & $\begin{array}{c}\text { Relative abundance } \\
(\%)\end{array}$ & $\begin{array}{c}\text { Total abundance } \\
\text { (ind 100 } \mathrm{m}^{-3} \text { ) }\end{array}$ & $\begin{array}{c}\text { Relative abundance } \\
(\%)\end{array}$ \\
\cline { 2 - 5 } & \multicolumn{2}{c}{ Summer 2008 } & \multicolumn{2}{c}{ Summer 2009 } \\
\hline Calanoid copepods & 74028 & 49 & 74064 & 38 \\
Cyclopoid copepods & 38525 & 24 & 72343 & 37 \\
Pteropods & 12648 & 8 & 3838 & 2.1 \\
Cnidarians & 10339 & 4 & 14380 & 7.5 \\
Ichthyoplankton & 6323 & 4 & 1054 & 0.5 \\
Euphausiids & 5361 & 3 & 8594 & 4.4 \\
Chaetognaths & 5321 & 2.5 & 5444 & 3.0 \\
Crustaceans (shrimps, & 2994 & 1.8 & 3036 & 1.5 \\
crabs, and lobsters larvae) & & & & \\
Salps & 3003 & 1.8 & 5387 & 2.5 \\
Ostracods & 1300 & 0.8 & 5258 & 2.6 \\
Appendicularians & 571 & 0.3 & 571 & 0.6 \\
Polychaetes & 365 & 0.2 & 359 & 0.2 \\
Heteropods & 214 & 0.1 & 252 & 0.1 \\
Amphipods & 121 & 0.07 & 160 & 0.1 \\
Cephalopods & 103 & 0.06 & 130 & 0.06 \\
Ctenophores & 95 & 0.05 & 121 & 0.06 \\
\hline
\end{tabular}
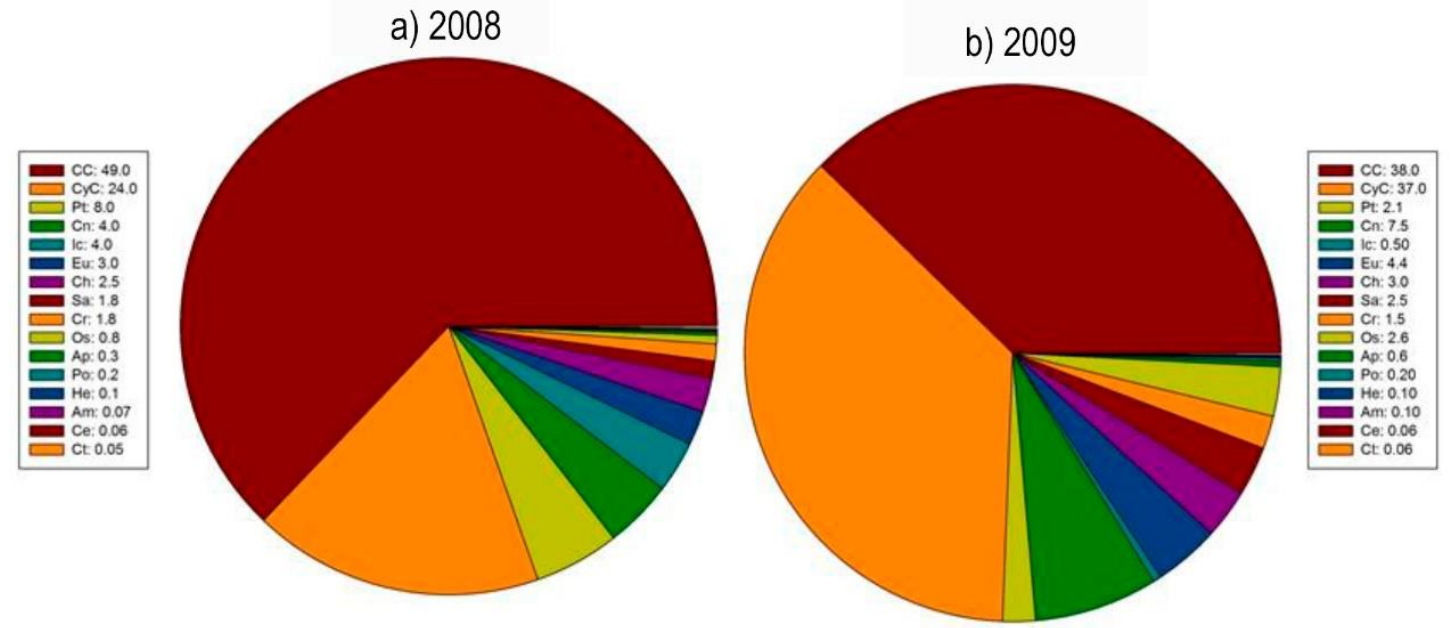

Figure 4. Relative abundance (\%) of each analyzed zooplankton group in the a) summer of 2008, and b) summer of 2009. CC: calanoid copepods, CyC: cyclopoid copepods, Pt: pteropods, Cn: cnidarians, Ic: ichthyoplankton, Eu: euphausiids, Ch: chaetognaths, Sa: salps, Cr: crustaceans, Os: ostracods, Ap: appendicularians, Po: polychaetes, He: heteropods, Am: amphipods; Ce: cephalopods, Ct: ctenophores.

cularly in the stations close to the connection with the Gulf of California. For example (Table 1, Fig. 4), it is clear that gelatinous organisms (cnidarians, chaetognaths, appendicularians, and ctenophores) showed an increment $(>3.5,0.5,0.3$, and $0.01 \%$, respectively) in their relative abundance in 2009, concerning 2008, associated with the increment in SST values in 2009, which was confirmed with the CCA ordination diagram (Fig. 6).
In this regard, it is widely known that both the vertical and horizontal compositions and the distribution of marine zooplankton depend on the temperature of the water column (which in turn determine movements of the water masses) as well as depend on the light intensity over a $24 \mathrm{~h}$ cycle, inducing diel vertical migrations of zooplankton in the ocean. Particularly, the temperature is strongly related to the biological cycles, growth, and metabolism of zooplankton orga- 

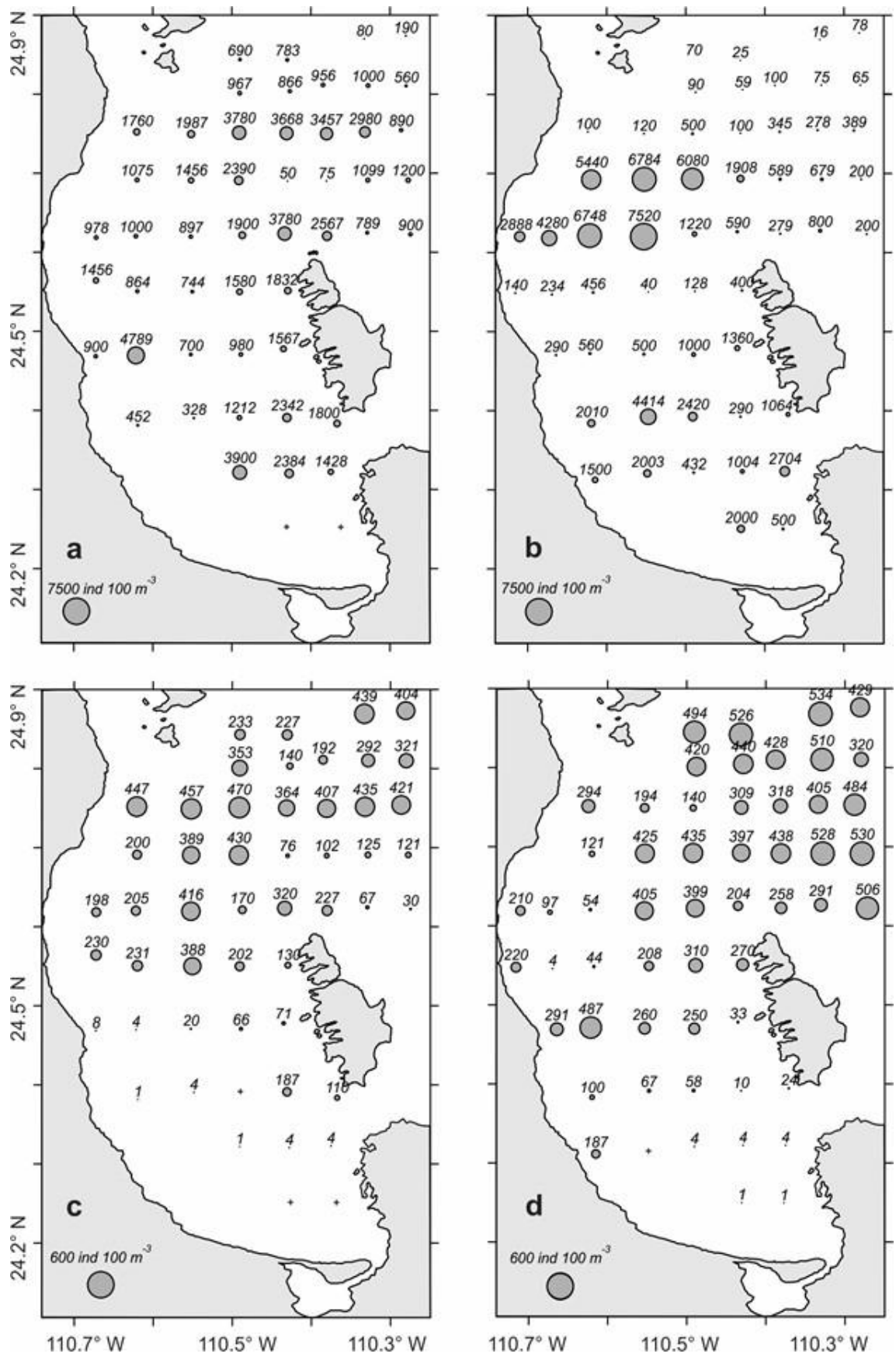

Figure 5. Horizontal distribution in ind $100 \mathrm{~m}^{-3}$. a) Calanoid copepods during the summer of 2008, b) calanoid copepods during the summer of 2009, c) cnidarians during the summer of 2008, and d) cnidarians during the summer of 2009.

nisms and the availability of food (phytoplankton) for zooplankton. Indeed, Youngbluth et al. (2008) observed an affinity of gelatinous zooplankton (medusae, ctenophores, siphonophores, appendicularians, and tunicates) that persist in specific water masses in the Mid-Atlantic Ridge; this agrees with our observations, in which differences in the SST between both summers were observed and associated with an increase in the relative abundance of the gelatinous zooplankton. Previous research on the effects of temperature on jellyfish has shown increased growth associated with higher temperatures (Webster \& Lucas, 2012). Similar observations were made by Riascos et al. (2013), who documented that increments in the temperature regimes may favor asexual reproduction (budding) and podocyst formation in jellyfish, with 

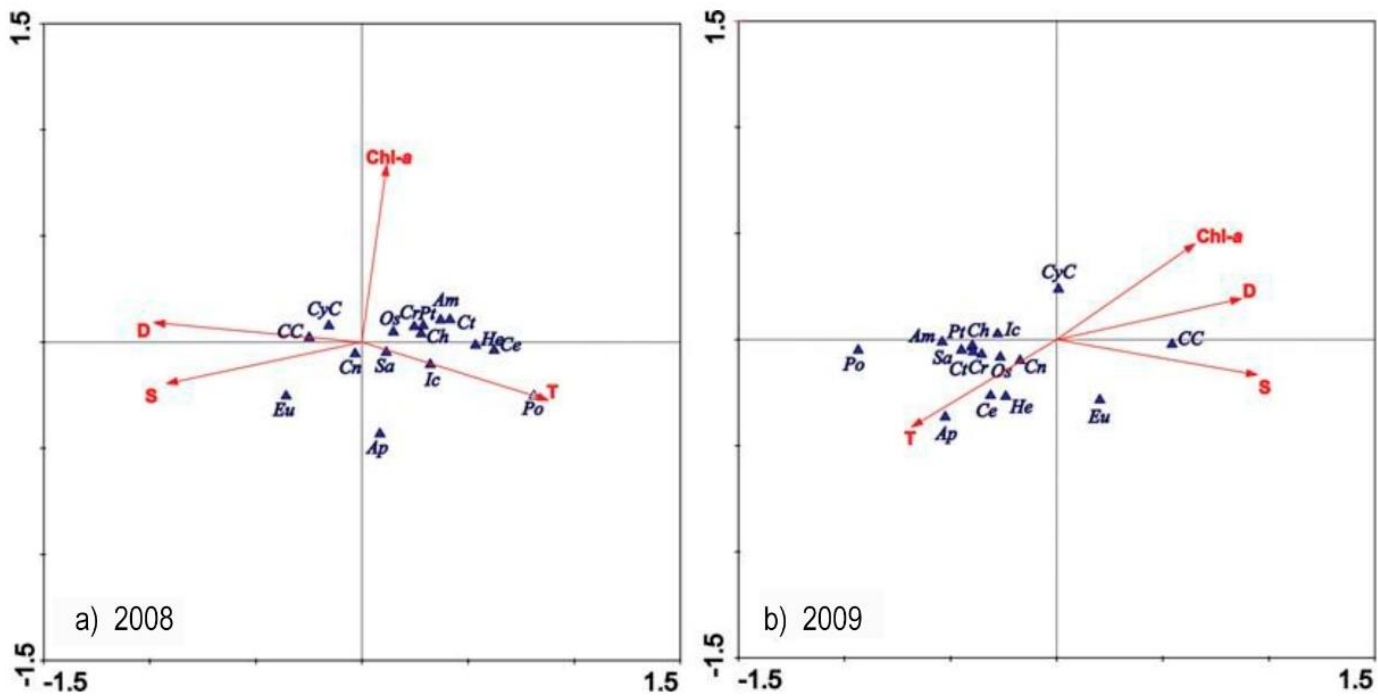

Figure 6. Canonical correspondence analysis diagrams. Red vectors indicate environmental variables: T: temperature $\left({ }^{\circ} \mathrm{C}\right)$; $\mathrm{S}$ : salinity; D: density $\left(\mathrm{kg} \mathrm{m}^{-3}\right)$; Chl- $a$ : chlorophyll- $a\left(\mathrm{mg} \mathrm{m}^{-3}\right)$; blue triangles represent the abundance for each zooplankton group (ind $100 \mathrm{~m}^{-3}$ ). The abbreviations are described in Figure 4.

strong impacts on the abundance of the medusa stage. In the Northern Adriatic Sea, high jellyfish's high abundances coincided with hot temperatures (Kogovsek et al., 2010). In the Mediterranean Sea, several holoplanktonic jelly species also have been unusually abundant in warm waters (Molinero et al., 2008). In the Chesapeake Bay, temperature changes have been associated with jellyfish blooms (Decker et al., 2007).

Cnidarians are not the only group to have been studied about increased temperatures. Field-based evidence has shown that the abundance of copepods (either calanoids or cyclopoids) changes with the water temperature in Port Phillip Bay, southern Australia (Jenkins \& Black, 2019). The composition and biomass of copepods from the Gulf of Gdansk (southern Baltic Sea) are also directly affected by water temperature, showing variations in biomass values as the temperature increases, which, in turn, determines the biological processes and affects variability, including the distribution, abundance, and biomass of copepods (Musialik-Koszarowska et al., 2019). The mesozooplankton fraction (mostly euphausiids and salps) was studied along a transect with high-temperature gradients in the eastern South Pacific Ocean, showing that these groups increase with temperature (González et al., 2019). A progressive migration across a thermal gradient was observed into the California Current, where the zooplankton groups, particularly euphausiids, benefit from favorable environments due to the temperature regime (Mackas et al., 1991). The Shannon-Weaver index results showed a slight difference between both summers, with lower values during 2009. This difference could be related to the increment in the temperature values, which could negatively affect the food availability (phytoplankton) for the herbivorous organisms.

The results presented here are also consistent with previous reports for the southern Gulf of California region, where a high variability in the zooplankton populations has been documented due to changes in the water column structure. For example, PalomaresGarcía et al. (2013) documented that the epipelagic copepods distribution is closely related to the water column's temperature, showing the highest abundances during the summertime (July). Contreras-Catala et al. (2016) evidenced a strong relationship between the mesopelagic fish larvae populations and the water column's stratification, which depends on the temperature distribution. More recently, Ambriz-Arreola et al. (2017) documented that the distribution of some euphausiids species is strongly related to the water column's thermal structure, with their maximum abundance close to the thermocline.

\section{CONCLUSIONS}

The observational evidence showed differences in the hydrographic parameters between both summers, with a higher temperature recorded in 2009. The zooplankton groups showed that the calanoid copepods were the most abundant group; however, there were important differences in the relative abundance of the rest of the 
analyzed groups due to the temperature distribution along the study area.

Based on the evidence presented here, gathered over consecutive summers from the Bay of $\mathrm{La} \mathrm{Paz}$, it is possible to envisage that, during the summer season, the zooplankton group composition will be dominated by copepods, calanoids, and cyclopoids. Then, depending on the temperature, some groups' predominance would be expected as a function of the heating; under this scenario, gelatinous zooplankton would be dominant.

\section{ACKNOWLEDGEMENTS}

The ship time of the research cruises DIPAL-II and DIPAL-III onboard the R/V El Puma was funded by Universidad Nacional Autónoma de México (UNAM). We thank the participants, officers, and crew of the R/V El Puma for their assistance in the seagoing expedition activities. Sergio Castillo Sandoval provided technical assistance during the laboratory analyses and Pablo Hernández-Alcántara in statistics. Helpful comments by three anonymous reviewers significantly improved the manuscript.

\section{REFERENCES}

Ambriz-Arreola, I., Gómez Gutiérrez, J., Franco Gordo, M.C., Palomares-García, R., Sánchez-Velasco, L., Robinson-Mendoza, C. \& Seibel, B. 2017. Vertical pelagic habitat of euphausiid species assemblages in the Gulf of California. Deep Sea Research Part I: Oceanographic Research Papers, 123(1): 75-89. doi: 10.1016/j.dsr.2017.03.008

Arreguín-Sánchez, F., Del Monte-Luna, P., Zetina-Rejón, M.J. \& Albañez-Lucero, O. 2017. The Gulf of California large marine ecosystem: fisheries and other natural resources. Environmental Development, 22: 71-77. doi: 10.1016/j.envdev.2017.03.002

Backus, R.H., Flierl, G.R., Kester, D.R., Olson, D.B., Richardson, P.L., Vastano, A.C., Wiebe, P.H. \& Wormuth, J.H. 1981. Gulf Stream Cold-core rings: their physics, chemistry, and biology. Science, 212(4499): 1091-1110. doi: 10.1126/science.212.44 99.1091

Boltovskoy, D. 1999. South Atlantic zooplankton. Publicaciones Especiales del INIDEP, Mar del Plata.

Brierley, A.S. 2017. Plankton. Current Biology, 27: R478R483. doi: 10.1016/j.cub.2017.02.045

Contreras-Catala, F., Sánchez Velasco, L., Beier, E., Godínez, V.M., Barton, E.D. \& Santamaría-del-Ángel, E. 2016. Effects of geostrophic kinetic energy on the distribution of mesopelagic fish larvae in the southern
Gulf of California in summer/fall stratified seasons. Plos One, 11(10): e0164900. doi: 10.1371/journal. pone. 0164900

Coria-Monter, E., Monreal-Gómez, M.A., Salas de León, D.A. \& Durán-Campos, E. 2018. Impact of the "Godzilla El Niño" event of the 2015-2016 on sea surface temperature and chlorophyll- $a$ in the southern Gulf of California, Mexico, as evidenced by satellite and in situ data. Pacific Science, 72(4): 411-422. doi: 10.2984/72.4.2

Coria-Monter, E., Monreal-Gómez, M.A., Salas-de-León, D.A., Aldeco-Ramírez, J. \& Merino-Ibarra, M. 2014. Differential distribution of diatoms and dinoflagellates in a cyclonic eddy confined in the Bay of La Paz, Gulf of California. Journal of Geophysical Research: Oceans, 119(9): 6258-6268. doi: 10.1002/2014JC00 9916

Coria-Monter, E., Monreal-Gómez, M.A., Salas de León, D.A., Merino-Ibarra, M. \& Durán-Campos, E. 2017. Wind-driven nutrient and subsurface chlorophyll- $a$ enhancement in the Bay of La Paz, Gulf of California. Estuarine, Coastal and Shelf Science, 196: 290-300. doi: 10.1016/j.ecss.2017.07.010

Cruz-Hernández, J., Sánchez-Velasco, L., Godínez, V.M., Beier, E., Palomares-García, J.R., Barton, E.D. \& Santamaría-del-Ángel, E. 2018. Vertical distribution of calanoid copepods in a mature cyclonic eddy in the Gulf of California. Crustaceana, 91(1): 63-84. doi: 10.1163/15685403-00003751

Decker, M.B., Brown, C.W., Hood, R.R., Purcell, J.E., Gross, T.F., Matanoski, J.C., Bannon, R.O. \& SetzlerHamilton, E.M. 2007. Predicting the distribution of the scyphomedusa Chrysaora quinquecirrha in the Chesapeake Bay. Marine Ecology Progress Series, 329: 99-113.

Durán-Campos, E., Monreal-Gómez, M.A., Salas de León, D.A. \& Coria-Monter, E. 2019. Zooplankton functional groups in a dipole eddy in a coastal region of the southern Gulf of California. Regional Studies in Marine Science, 28: 100588. doi: 10.1016/j.rsma. 2019.100588

Durán-Campos., E., Monreal-Gómez, M.A., Salas de León, D.A. \& Coria-Monter, E. 2020. Field and satellite observations on the seasonal variability of the surface chlorophyll- $a$ in the Bay of La Paz, Gulf of California, Mexico. International Journal of Oceans and Oceanography, 14(1): 157-167.

Durán-Campos, E., Salas de León, D.A., Monreal-Gómez, M.A., Aldeco-Ramírez, J. \& Coria-Monter, E. 2015. Differential zooplankton aggregation due to relative vorticity in a semi-enclosed bay. Estuarine, Coastal and Shelf Science, 164: 10-18. doi: 10.1016/j.ecss. 2015.06.030 
Estrada, R., Harvey, M., Gosselin, M., Starr, M., Galbraith, P.S. \& Straneo, F. 2012. Late-summer zooplankton community structure, abundance, and distribution in the Hudson Bay system (Canada) and their relationships with environmental conditions, 2003-2006. Progress in Oceanography, 101(1): 121145. doi: 10.1016/j.pocean.2012.02.003

García-Mirafuentes, S. 2010. Análisis de las características del giro ciclónico de la Bahía de La Paz. Tesis de Maestría, Universidad Nacional Autónoma de México, Ensenada, 86 pp.

González, C.E., Escribano, R., Bode, A. \& Schneider, W. 2019. Zooplankton taxonomic and trophic community structure across biogeochemical regions in the Eastern South Pacific. Frontiers in Marine Science, 5: 498. doi: 10.3389/fmars.2018.00498

Jenkins, G.P. \& Black, K.P. 2019. Contrasting impact of diatoms on dominant calanoid and cyclopoid copepods in a temperate bay. Estuarine, Coastal and Shelf Science, 217: 211-217. doi: 10.1016/j.ecss.2018. 11.019

Johnson, A.F., Gonzales, C., Townsel, A. \& CisnerosMontemayor, A.M. 2019. Marine ecotourism in the Gulf of California and the Baja California Peninsula: research trends and information gaps. Scientia Marina, 83(2): 177-185. doi: 10.3989/scimar.04880.14A

Kogovsek, T., Bogunovic, B. \& Malej, A. 2010. Recurrence of bloom-forming Scyphomedusae: wavelet analysis of a 200-year time-series. Hydrobiologia, 645: 81-96.

Kramer, D., Kalin, M.J., Stevens, E.G., Thrailkill, J.R. \& Zweifel, J.R. 1972. Collecting and processing data on fish eggs and larvae in the California Current. NOAA Technical Report NMFS Circ., vol. 370, pp. 1-38.

Lavín, M.F., Castro, R., Beier, E., Godínez, V.M., Amador, A. \& Guest, P. 2009. SST, thermohaline structure, and circulation in the southern Gulf of California in June 2004 during the North American Monsoon Experiment. Journal of Geophysical Research, 114: C02025. doi:10.1029 /2008JC004896

McGowan, J.A. \& Fraundorf, V.J. 1996. The relationship between size of net and estimates of zooplankton diversity. Limnology and Oceanography, 11(4): 456469. doi: 10.4319/lo.1966.11.4.0456

Mackas, D.L., Washburn, L. \& Smith, S.L. 1991. Zooplankton community pattern associated with a California Current cold filament. Journal of Geophysical Research, 96(C8): 14781-14797. doi: 10.1029/91JC01037

Magurran, A. 2004. Measuring biological diversity. Blackwell, Oxford.

Mauchline, J., Blaxter, J.H.S., Southward, A.J. \& Tyler, P.A. 1998. The biology of calanoid copepods. Academic Press, San Diego.
Mercado-Santana, J.A., Santamaría-del-Ángel, E., González-Silvera, A., Sánchez-Velasco, L., GraciaEscobar, M.F., Millán-Núñez, R. \& Torres, C.R. 2017. Productivity in the Gulf of California large marine ecosystem. Environmental Development, 22: 18-29. doi: 10.1016/j.envdev.2017.01.003

Molinero, J.C., Buecher, E., Lucic, D., Malej, A. \& Miloslavic, M. 2008. Climate and Mediterranean jellyfish: assessing the effect of temperature regimes on jellyfish outbreak dynamics. Annales Series Historia Naturalis, 19: 11-18.

Monreal-Gómez, M.A., Molina-Cruz, A. \& Salas de León, D.A. 2001. Water masses and cyclonic circulation in Bay of La Paz, Gulf of California, during June 1998. Journal of Marine Systems, 30(3-4): 305-315. doi: 10.1016/S0924-7963(02)00075-1

Musialik-Koszarowska, M., Dzierzbicka-Glowacka, L. \& Weydmann, A. 2019. Influence of environmental factors on the population dynamics of key zooplankton species in the Gulf of Gdansk (southern Baltic Sea). Oceanologia, 61: 17-25. doi: 10.1016/j.oceano.2018. 06.001

Ortiz-Burgos, S. 2016. Shannon-Weaver Diversity Index. In: Kennish, M.J. (Ed.). Encyclopedia of estuaries. Encyclopedia of Earth sciences series. Springer, Dordrecht.

Páez-Osuna, F., Sánchez-Cabeza, J.A., Ruiz-Fernández, A.C., Alonso-Rodríguez, R., Piñón-Gimate, A., Cardoso-Mohedano, J.G., et al. 2016. Environmental status of the Gulf of California: a review of responses to climate change and climate variability. Earth Science Reviews, 162: 253-268. doi: 10.1016/j.earscirev.2016. 09.015

Paffenhöfer, G.A. 1993. On the ecology of marine cyclopoid copepods (Crustacea, Copepoda). Journal of Plankton Research, 15(1): 37-55. doi: 10.1093/plankt/ 15.1.37

Palomares-García, R., Gómez-Gutiérrez, J. \& Robinson, C.J. 2013. Winter and summer vertical distribution of epipelagic copepods in the Gulf of California. Journal of Plankton Research, 35(5): 1009-1026. doi: 10.1093/ plankt/fbt052

Pardo, M.A., Silverberg, N., Gendron, D., Beier, E. \& Palacios, D.M. 2013. Role of environmental seasonality in the turnover of a cetacean community in the southwestern Gulf of California. Marine Ecology Progress Series, 487: 245-260. doi: 10.3354/meps 10217

Pieri, M., Massi, L., Lazzara, L., Nuccio, C., Lapucci, C. \& Maselli, F. 2015. Assessment of three algorithms for the operational estimation of [CHLA] from MODIS data in the Western Mediterranean Sea. European Journal of Remote Sensing, 48: 383-401. doi: 10.5721/ EuJRS20154822 
Riascos, J.M., Paredes, L., González, K., Cáceres, I. \& Pacheco, A.S. 2013. The larval and benthic stages of the scyphozoan medusa Chrysaora plocamia under El Niño-La Niña regimes. Journal of Experimental Marine Biology and Ecology, 446: 95-101. doi: 10.1016/j.jembe.2013.05.006

Richardson, A.J. 2008. In hot water: zooplankton and climate change. ICES Journal of Marine Science, 65(3): 279-295. doi: 10.1093/icesjms/fsn028

Salas de León, D.A., Carbajal, N., Monreal-Gómez, M.A. \& Gil-Zurita, A. 2011. Vorticity and mixing induced by the barotropic M2 tidal current and zooplankton biomass distribution in the Gulf of California. Journal of Sea Research, 66: 143-153. doi: 10.1016/j.seares. 2011.05.011

Silverberg, N., Aguirre-Bahena, F. \& Mucci, A. 2014. Time-series measurements of settling particulate matter in Alfonso Basin, La Paz Bay, southwestern Gulf of California. Continental Shelf Research, 84: 169-187. doi: 10.1016/j.csr.2014.05.005

Ter Braak, C.J.F. 1986. Canonical correspondence analysis: a new eigenvector technique for multivariate direct gradient analysis. Ecology, 67: 1167-1179. doi: $10.2307 / 1938672$

Trégouboff, G. \& Rose, M. 1957. Manuel de planctonologie Méditerranéenne. Centre National de la Recherche Scientifique, Paris.

Received: March 3, 2020; Accepted: July 7, 2020
Turner, J.T. 1986. Zooplankton feeding ecology: contents of fecal pellets of the cyclopoid copepods Oncaea venusta, Corycaeus amazonicus, Oithona plumifera, and $O$. simplex from the northern Gulf of Mexico. Marine Ecology, 7(4): 289-302. doi: 10.1111/j.14390485.1986.tb00165.x

Vidal, J. 1980. Physioecology of zooplankton. II. Effects of phytoplankton concentration, temperature, and body size on the development and molting rates of Calanus pacificus and Pseudocalanus sp. Marine Biology, 56: 135-146. doi: 10.1007/BF00397130

Webster, C.N. \& Lucas, C.H. 2012. The effects of food and temperature on settlement of Aurelia aurita planula larvae and subsequent somatic growth. Journal of Experimental Marine Biology and Ecology, 436: 50-55. doi: 10.1016/j.jembe.2012.08.014

Youngbluth, M., Sornes, T., Hosia, A. \& Stemmann, L. 2008. Vertical distribution and relative abundance of gelatinous zooplankton, in situ observations near the Mid-Atlantic Ridge. Deep-Sea Research Part II Topical Studies in Oceanography, 55: 119-125. doi: 10.1016/j.dsr2.2007.10.002 